Ethiopian Journal of Environmental Studies \& Management 8(Suppl. 2): 855 - 873, 2015.

ISSN:1998-0507

doi: http://dx.doi.org/10.4314/ejesm.v8i2.1S

Submitted: February 06, 2015

Accepted: October 23, 2015

\title{
VEGETATION COVER CHANGE DETECTION OF LAPAI NIGER STATE, NIGERIA USING REMOTE SENSING IMAGE
}

\author{
*DANGANA, K., ASIRIBO-SALLAU, O.R. AND HALILU, P.H. \\ Department of Geography, Ibrahim Badamasi Babangida University, Lapai Niger State, \\ Nigeria
}

\begin{abstract}
Landsat-7 images (ETM+) of 2001 and 2006 and Nigeriasat-1 images of 2012 were used for recognition of vegetation reflectance, layer stacking of band 4, 3 and 2 (false color composite) for ETM+ and 3, 2, 1(false color composite) for Nigeriasat-1 was performed. GCP were taken with a GPS device in strategic locations of the study area; this was to establish ground information on vegetation cover. The images were classified into dense vegetation, savanna orchard bush, and grassland/cropland, exposed land, built up area and water body. The GCP were plotted on ETM+ which was used to evaluate the vegetation change in Nigeriasat-1 images. Supervised classification was done and maximum likelihood operation was performed to generate vegetation cover maps. Afterwards, vegetation cover map of 2001 and 2012, were crossed to generate the map of change of vegetation cover for the respective dates and to find out the changing pattern of vegetation cover. The accuracy of the classification was done to assess a confusion matrix. Additionally, the use of spectral vegetation index, namely the Normalized Difference Vegetation Index (NDVI) was applied to detect areas of vegetation cover decrease. The study then reveals that vegetation cover of the area has changed significantly during 2001 to 2012; it is therefore recommended that the decline in the vegetation call for coercive environmental protection policies to relieve human pressure on vegetation and for this reason the policy should be enforced.
\end{abstract}

Key Words: Classification, Normalized, Reflectance, Remmendation, Vegetation Supervised

\section{Introduction}

In developing countries where a large proportion of human population depend almost entirely on natural resources for their livelihoods, resulting in land-use and cover changes. There are increasing concerns for sustainable management of the land resources (e.g., natural vegetation). Assessing and monitoring the state of the earth surface is a key requirement for global change "Committee on Global Change Research, National Research Council 1999" (Campbell, 2002).

Urban growth, in population has been a major factor that has altered natural vegetation cover, due to anthropogenic activities. The results of these have left significant effects on local weather and climate. In remote sensing technology change detection refers to the process of identifying differences in the state of land features by observing them at different times. Remote sensing data can provide 
reliable information on vegetation cover. Singh (1989) described change detection as a process that observes the differences of an object or phenomenon at different times. Land use and land cover has become increasingly important as the Nation plans to overcome the problems of haphazard, uncontrolled development, deteriorating environmental quality, loss of prime agricultural lands, destruction of important wetlands and loss of fish and wildlife habitat. One of the prime prerequisites for better use of land information on existing land use patterns and changes in land use through time. Since Land cover and land use change is not an event but a process, it can be understood and forecasted quite well before time. Knowledge of the present distribution and area of such agricultural, recreational and urban lands as well as information on their changing proportions $\mathrm{s}$ needed by legislators, planners, and local government official to determine better land use policy. (Lillesand and Keifer, 1994).

The aim of the study is to generate a vegetation map and to detect the changes of vegetation for a period of eleven years from 2001 to 2012 at Lapai Niger state, Nigeria using remote sensing data. In order to determine the changes in vegetation that has occurred since 2001.

\section{Conceptual Frame work}

The conceptual basis for this research is the recognition that tropical cities like Lapai are located at the higher end of the, energy/matter consumption and pollution or "anthropogenic ecosystem spectrum" (AES), which is linked to increased vegetation change. Within these urbanized landscapes energy gradients are experienced from the peri-urban, with fragmented native and some introduced vegetation, through suburban landscapes, with predominance of exotic vegetation, to commercial and industrial landscapes with little if any vegetation cover. These anthropogenic ecosystems have also evolved out of low energy, native vegetation dominated predecessors which still persist elsewhere, as aboriginal land, conservation reserves, closed catchments and pastoral land, and as consequence have inherited some of their attributes to which new attributes have been added increasing their complexity. Classical ecological theory underpinning such Ecological Sustainable Development (ESD) thinking however is somewhat mechanistic and deterministic seeing homeostatic, stable conditions as the norm. This gives rise to the concept of "sustainable", being suggestive of a perpetual motion machine of the dynamism of vegetation cover (Rosenberg et al., 1984).

\section{Statement of the Problem}

With the growing concern of global climate change, regional to global landcover mapping has become an increasingly important data source in a variety of studies such as land-cover change, biogeochemical cycle modeling and climate modeling. The global change research community is increasingly organized in their call for the development of global land-cover. The International GeosphereBiosphere Programme (IGBP), for example, has identified land-cover as a top research priority (Dimyati, 1995).

The study area (lapai), has witnessed remarkable expansion in growth and developmental activities such as building, road construction, deforestation and many other anthropogenic activities as a result of the establishment of the state University, this various practices are responsible for destruction of vegetation. It is therefore necessary for a study such as this to be carried out if lapai will avoid the associated problems of growing and expanding town like many others in the world. 


\section{Justification of Study}

Past decades have witnessed a rapid development in technologies related to the exploitation of natural resources. This in turn has resulted in vast and unexpected increase in human abilities to access and use ever more remote areas for those resources. Coupled with the premises, population increase has also created more demands for goods and services derived directly from natural resources. As one of the consequences, vegetation cover has shrunk as a result of search of more wood products and agricultural lands. Hence, the plant and animal species associated with the vegetation have been threatened by extinction.

As human and natural forces modify the landscape, resource agencies find it increasingly important to monitor and assess these alterations. Changes in vegetation affect wildlife habitat, fire conditions, aesthetic and historical values and ambient air quality. These changes, in turn, influence management and policy decisions. Methods for monitoring vegetation change range from intensive field sampling with plot inventories to extensive analysis of remotely sensed data are important ingredients for development. While aerial photography can detect change over relatively small areas at reasonable cost, satellite imagery has proven more cost effective for large regions. Therefore, the result of this research is vital developmental decisions by the policy makers and managers of our environment.

\section{Aim and Objectives}

The aim of the study is to generate a vegetation map and to detect the changes of vegetation for a period of eleven years from 2001 to 2012 at Lapai Niger state, Nigeria using remote sensing data. The following objectives are put ward accordingly:

- To identify vegetation cover, their spatial distribution and analyze vegetation phenology and dynamics

- To perform NDVI calculation, showing Vegetation reflectance.

- To produce a land use/Landover map.

\section{Study Area}

Lapai is located within latitude $9^{\circ} 02^{\prime}$ $\mathrm{N}$ and longitude $6^{\circ} 34^{\prime \prime} \mathrm{E}$, it is about $18 \mathrm{~km}$ west of old lapai near Gurara River along Suleja road and about 56km East of Minna Niger state capital. Lapai covers an area of $3,730 \mathrm{~km}^{2}$ with a population of 53,687 (Gazeted 2006 Census report by National Population Commission). Lapai local government area is one of the twenty-five main local governments in Niger State. Figure 1 below, is map of Nigeria showing Niger State location, while figure 2 is Niger State showing the location of the study area i.e Lapai Local Government Area. 


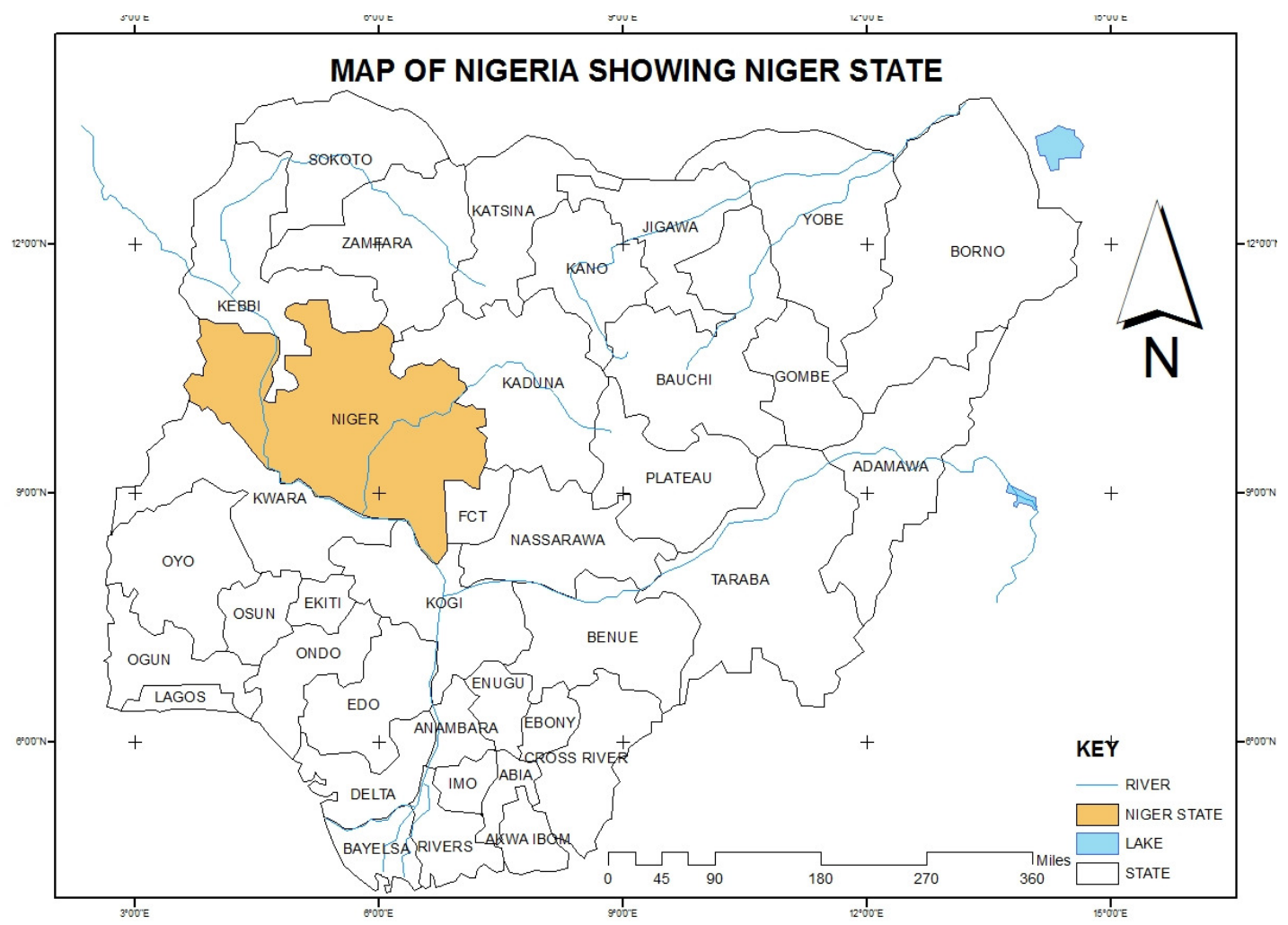

Figure 1: Political Map of Nigeria Showing the Location of Niger State

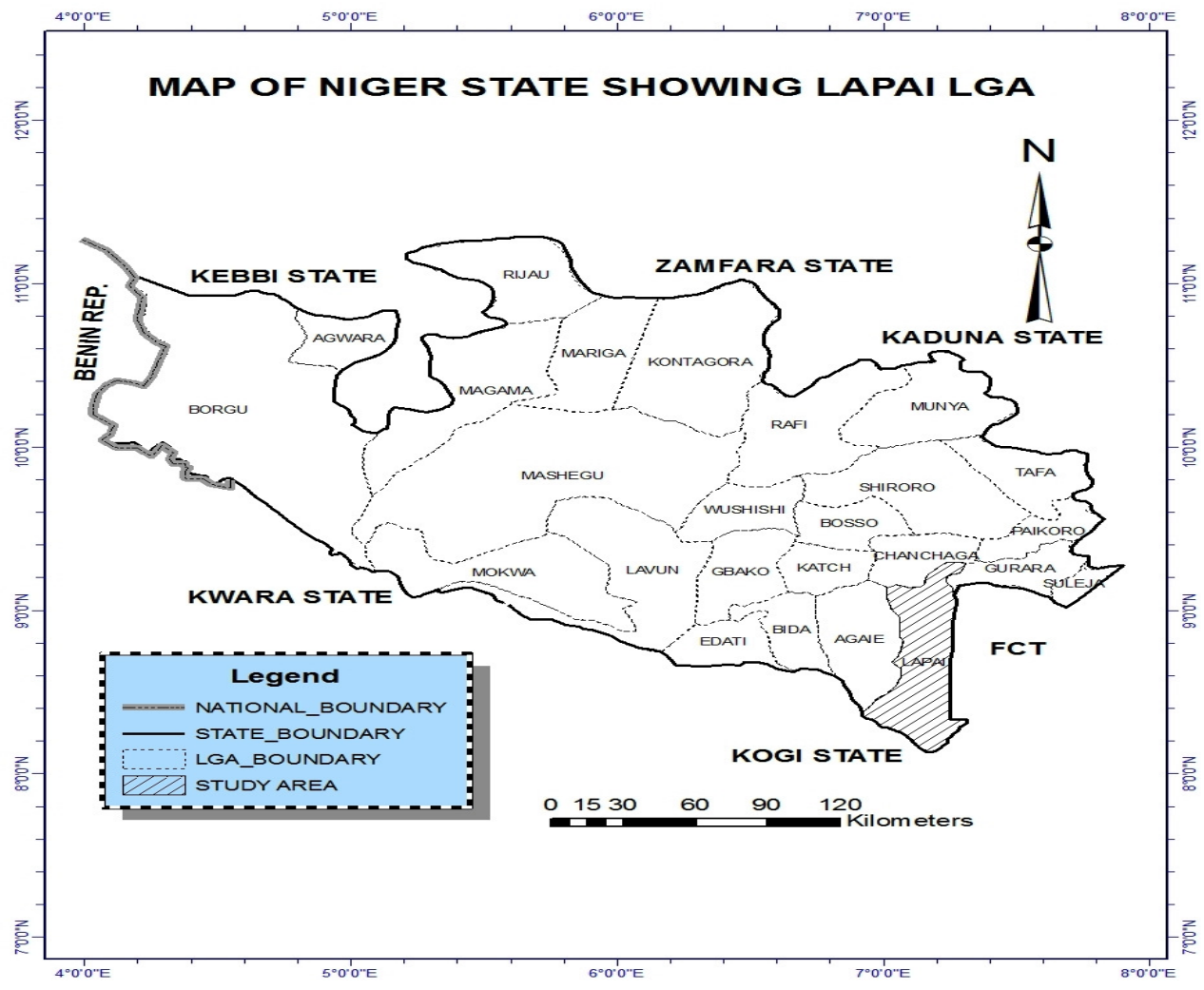

Figure 2 Political Map of Niger State showing the Location of Lapai 


\section{Climate}

The study area is located in a tropical climate which is characterized by two distinct seasons in a year, the wet and dry seasons. The area has an annual rainfall of less than $1000 \mathrm{~mm}$, where rainy season which occurs between April and September with Peak Periods between October and March, a period of six months. The temperature in lapai varies within the seasons, during the dry seasons the area record high temperature between $30^{\circ} \mathrm{c}$ and $36^{\circ} \mathrm{c}$ which last from December to April, while in the rainy season, the area experience low temperature between $26^{\circ} \mathrm{c}$ and $30^{\circ} \mathrm{c}$, highest within the season occurring at mid-day between May - July.

\section{Vegetation Cover}

The natural vegetation of the study area belongs to the parkland guinea savanna vegetation characterized by a mixture of tree, shrubs and tall grasses forming a natural habitat or game and provides for a beautiful land scale and scenery, examples of common trees found in this area are: Gmelina spp, Locust Bean, Shea Butter trees, Isoberlina etc. several years of cultivation coupled with effect of soil erosion have profoundly reduced the density of vegetation cover.

\section{Land Use}

The people are predominantly Nupe's with farming as the main occupation. The area lacks major manufacturing industries, and thus the people depend largely on agriculture. The climate, soil, and hydrology of the area permit the cultivation of most Nigerian staple crops. Therefore, the major land use in the area is agricultural land use, other land use in the area includes residential, institutional, commercial, transportation, open/vacant space and utilities land use. Land use and land management practices have major impact on natural resources including water, soil nutrients, plants and animals. The major effects of land use on land cover has been deforestation, more recently significant effects of land use include urban sprawl, soil erosion, soil degradation, salinization and desertification. Land use changes, together with the use of fossil fuels are the major anthropogenic sources of carbon dioxide, a dominant greenhouse gass.

\section{Methodology}

Digital image-processing software Arc GIS 9.3 and ILWIS 3.3 were used for the processing, analysis and integration of spatial data to achieve the objectives of the study.ILWIS 3.3 was used to generate the false color composite, by combining near infrared, red and green which are bands 4 , 3, 2 together for both images. This was done for vegetation recognition, because chlorophyll in plants reflects very well to near infrared than the visible. Normalized Difference Vegetation index (NDVI) was performed. NDVI can be calculated as a ratio of red and near infrared bands of a sensor system.

NDVI $=$ (near infrared band- red band)/ (near infrared band+ red band NDVI values range from -1.0 to 1.0 . As a result NDVI values between -1.0 and 0 represents non- vegetative features such as bare surface, built- up area and water body. Conversely, greater than 0 display vegetation covers. To find out the changing pattern of vegetation during 2001- 2012both images were crossed in ILWIS environment.

\section{Sources of Data}

The Landsat 7 ETM+ satellite images of the year 2001 and 2006 of Niger state was obtained from the Global Land cover Facility (GLCF) an Earth Science Data Interface, while that of 2012 was obtained from the National Space Research and Development Agency in Abuja (NASRDA). Characteristics of the data are shown in table 1. 
Vegetation Cover Change Detection of Lapai Niger State................DANGANA et al.

Table 1: Data Characteristics

\begin{tabular}{llllllll}
\hline Satellite & Source & Sensor & \multicolumn{2}{l}{ Band used } & & Year & Resolution \\
\hline Landsat-7 & GLCF & ETM+ & (NIR, & Red, & Green $)$ & 2001 & $30 \mathrm{~m}$ \\
& & & $4,3,2$ & & & \\
Landsat-7 & GLCF & ETM+ & (NIR, Red, & Green $)$ & 2006 & $30 \mathrm{~m}$ \\
& & & $4,3,2$ & & & \\
Nigeriasat-2 & NASRDA & & $(\mathrm{NIR}, \quad$ Red, & Green $)$ & 2012 & $32 \mathrm{~m}$ \\
& & & $3,2,1$ & & & & \\
\hline
\end{tabular}

\section{Image Classification}

For the objective of this work, three data layers (Band 4, 3, 2 of the ETM+ image and Band 3, 2, 1 of the Nigeriasat-2) were stacked together and used for supervised classification. Supervised maximum likelihood classifications were applied to all the datasets to generate classification clusters. However, nonvegetated lands (e.g., bare soils, infrastructure, and water) have significantly different spectral signatures compared to vegetation types. Mature forests have different features that can be separated from non-forest vegetation (e.g., successional forests, agroforestry, perennial plantations, and pastures). Water has very low reflectance values in NIR and SWIR bands, urban or bare soils have higher reflectance values than other classes in visible and SWIR bands, and mature forests have lower reflectance values than non-forest vegetation types in NIR and SWIR bands. The six land-cover classes (Dense forest, Savanna Orchard Bush, Grassland/Cropland, Built up Area, Expose Land and Water Body) were classified with a Maximum Likelihood classification. The normalized difference vegetation index [i.e., NDVI _ (NIR _ red)/(NIR _ red)] image calculated from ETM+ and Nigeriasat-2 image was also used in image classification. A statistical analysis (minimum, maximum, mean, and standard deviation) for each class was conducted, and thresholds were determined based on the comprehensive analysis of multispectral signatures.

\section{Extracting region of Interest}

Lapai town is extracted from the Niger State Image since it is the study area. Lapai LGA was first extracted by Masking in Arc Map 9.3 Software. Though the aim is to extract Lapai town, to extract the region of Interest, the extracted map of Lapai LGA was imported into ILWIS 3.3 Academic software and formula used below was used to extracts the submap of Lapai town. Output = Map Submap (input, $2273,3292,238,381)$. Where, Input is the name of the input map (Niger) (2273, $3292,238,381)$ are the extents of columns and rows. Output is extracted submap of Lapai town.

\section{Data Analysis}

Satellite data available were adapted to the surface of the study area which is the most representative section of the study area. Three main methods of data analysis were adopted in this study of Vegetation classification (I) NDVI Calculation Overlay operation (III) Accuracy Assessment 


\section{Flow Chart of Methodology}

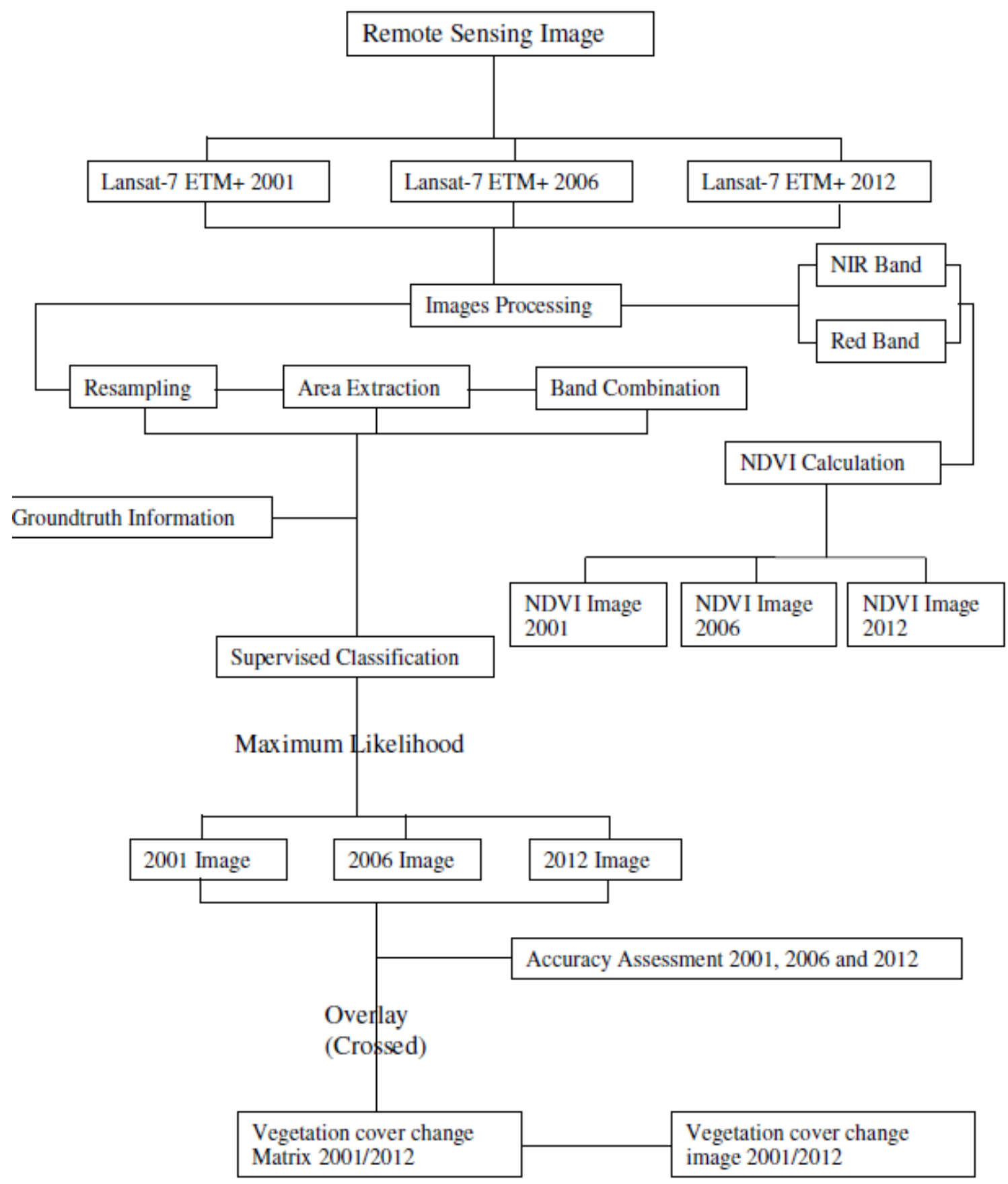

Vegetation Classification

Premised on the objective of this study, vegetation cover over the study area has changed. The above mentioned methods for analysis have proved this change. The results of the maximum likelihood supervised classification for the years 2001, 2006 and 2012 are illustrated in the Figures 3, 4, and 5 respectively. 


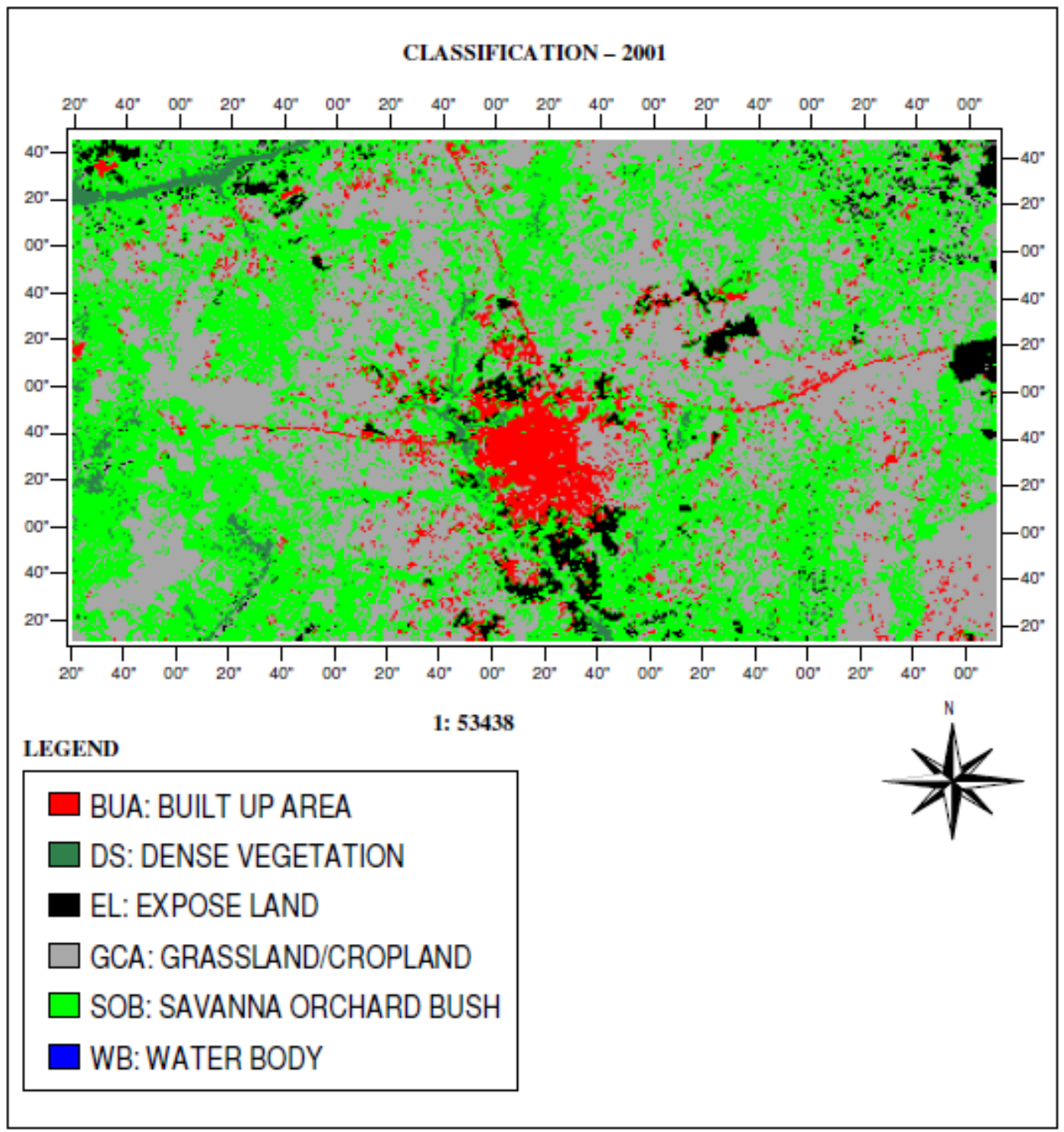

Figure 3: Land Cover Map of the Year, 2001 


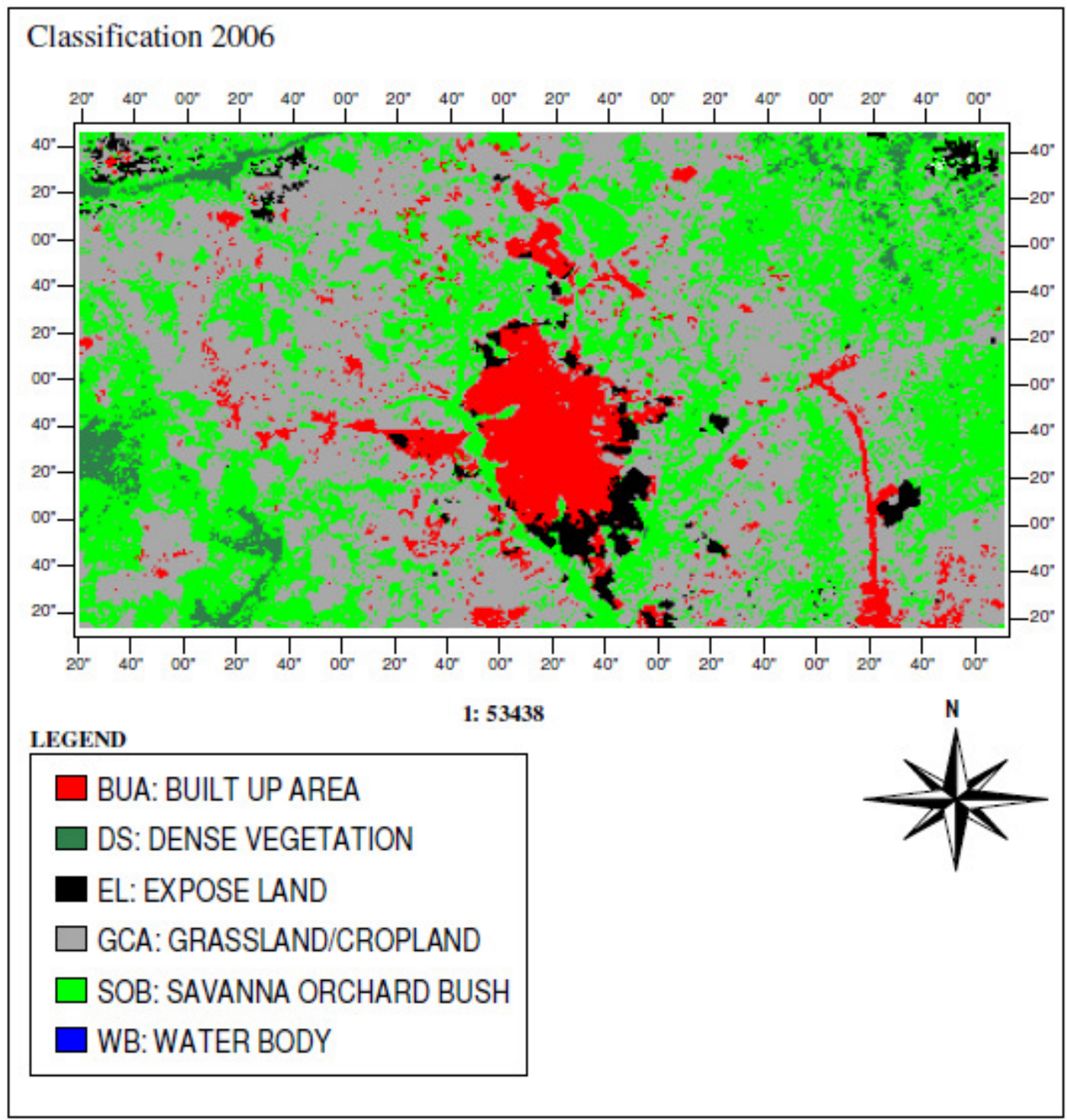

Figure 4: Land Cover Map of the Year, 2006 


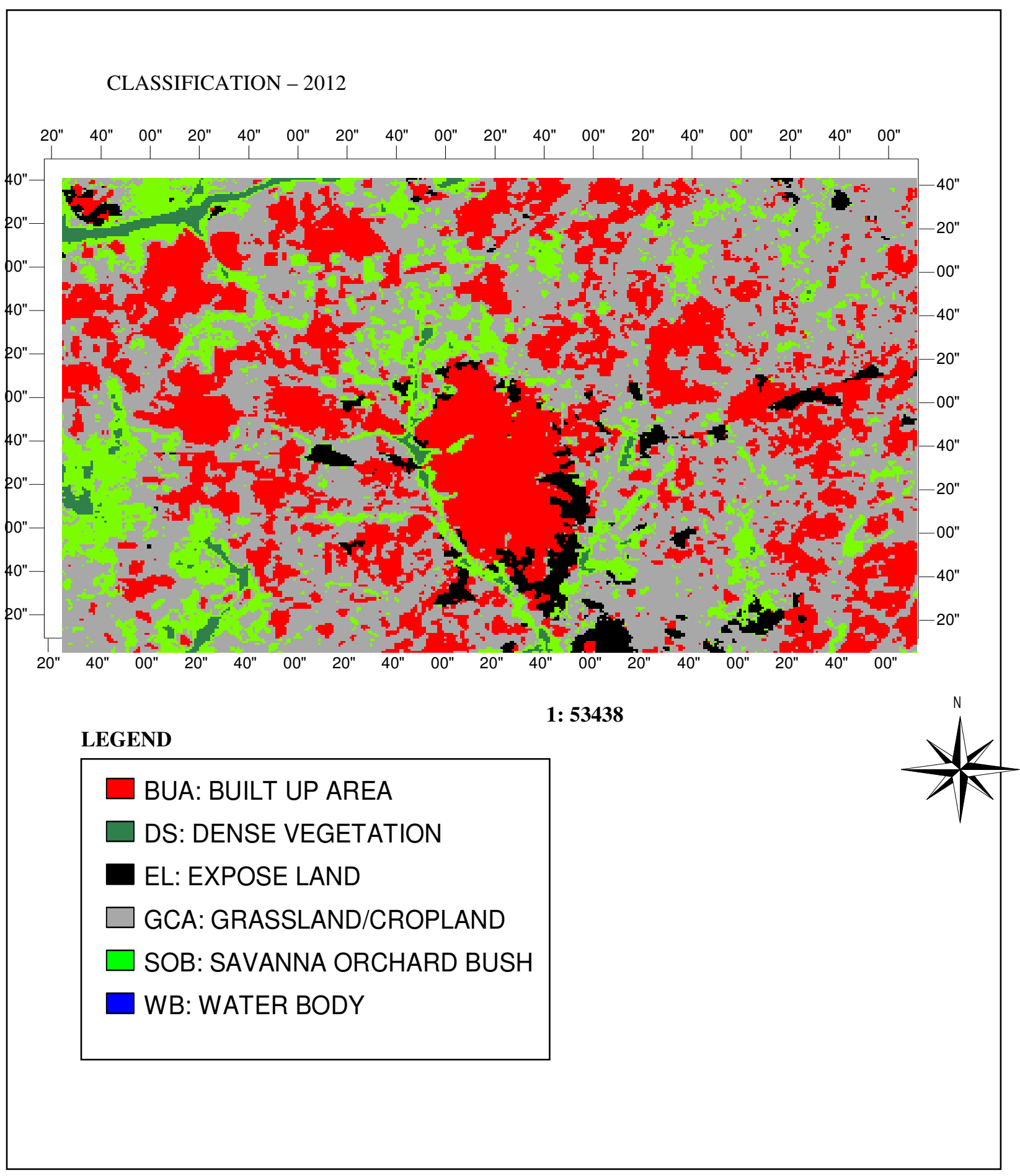

Figure 5: Land cover map of the year 2012 
Table 2: Showing the extent of land cover after classification from 2001 - 2006

\begin{tabular}{llllll}
\hline $\begin{array}{l}\text { Land cover } \\
\text { types }\end{array}$ & $\begin{array}{l}\text { 2001Areas in } \\
\text { hectares }\end{array}$ & $\begin{array}{l}\text { \% of the } \\
\text { area }\end{array}$ & $\begin{array}{l}\text { 2006Areas in } \\
\text { hectares }\end{array}$ & $\begin{array}{l}\text { \% of the } \\
\text { area }\end{array}$ & $\begin{array}{l}\text { \% change between } \\
\text { the years }\end{array}$ \\
\hline BUA & 309.87 & 4.21 & 470 & 6.54 & 2.33 increase \\
EL & 2327.26 & 4.3 & 247.25 & 3.36 & 0.94 decrease \\
DS & 411 & 5.58 & 193.72 & 2.61 & 2.97 decrease \\
SOB & 2327.26 & 31.6 & 3202.13 & 43.49 & 11.89 increase \\
GCL & 4000.41 & 54.31 & 3241.28 & 44.01 & 10.3 decrease \\
WB & 0 & 0 & 0 & 0 & \\
\hline
\end{tabular}

Table 3: Showing the extent of land cover after classification from 2006 - 2012

\begin{tabular}{llllll}
\hline $\begin{array}{l}\text { Land cover } \\
\text { types }\end{array}$ & $\begin{array}{l}\text { 2006Areas in } \\
\text { hectares }\end{array}$ & $\begin{array}{l}\text { \% of the } \\
\text { area }\end{array}$ & $\begin{array}{l}\text { 20012Areas in } \\
\text { hectares }\end{array}$ & $\begin{array}{l}\text { \% of the } \\
\text { area }\end{array}$ & $\begin{array}{l}\text { \% change between } \\
\text { the years }\end{array}$ \\
\hline BUA & 470 & 6.54 & 2289.25 & 31.08 & 24.54 increase \\
EL & 247.25 & 3.36 & 283.40 & 3.85 & 0.49 increase \\
DS & 193.72 & 2.61 & 119 & 1.62 & 0.99 decrease \\
SOB & 3202.13 & 43.49 & 1067.30 & 14.49 & 29 decrease \\
GCL & 3241.28 & 44.01 & 3606.39 & 48.96 & 4.95 increase \\
WB & 0 & 0 & 0 & 0 & 0 \\
\hline
\end{tabular}

Table 4: Showing the extent of land cover after classification from 2001- 2012

\begin{tabular}{llllll}
\hline $\begin{array}{l}\text { Land cover } \\
\text { types }\end{array}$ & $\begin{array}{l}\text { 2001Areas in } \\
\text { hectares }\end{array}$ & $\begin{array}{l}\text { \% of the } \\
\text { area }\end{array}$ & $\begin{array}{l}\text { 20012Areas in } \\
\text { hectares }\end{array}$ & $\begin{array}{l}\% \text { of the } \\
\text { area }\end{array}$ & $\begin{array}{l}\text { \% change between } \\
\text { the years }\end{array}$ \\
\hline BUA & 309.87 & 4.21 & 2289.25 & 31.08 & 26.87 increase \\
EL & 2327.26 & 4.3 & 283.40 & 3.85 & 0.45 decrease \\
DS & 411 & 5.58 & 119 & 1.62 & 3.96 decrease \\
SOB & 2327.26 & 31.6 & 1067.30 & 14.49 & 17.11 decrease \\
GCL & 4000.41 & 54.31 & 3606.39 & 48.96 & 5.35 decrease \\
WB & 0 & 0 & 0 & 0 & 0 \\
\hline
\end{tabular}

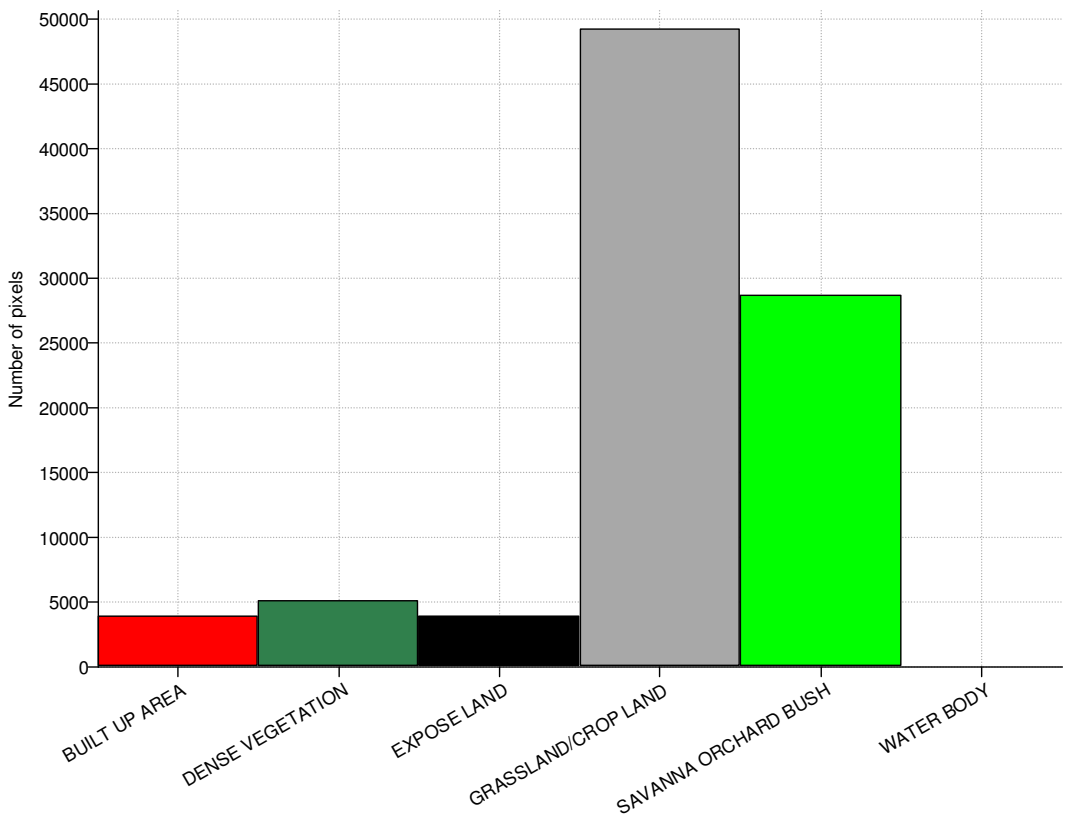

Figure 6: Histograms 2001 (ETM+) 


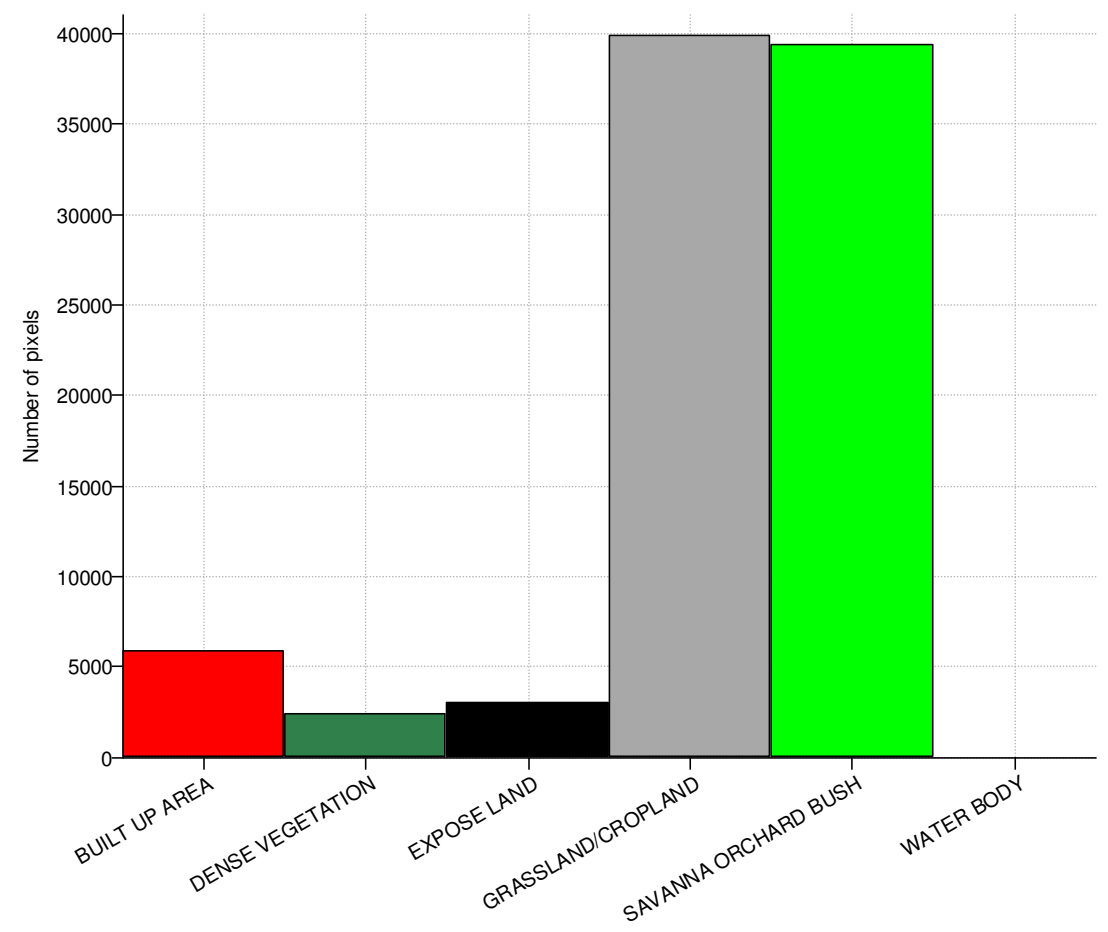

Figure 7: Histograms 2006 (ETM+) Showing Land Uses in Lapai

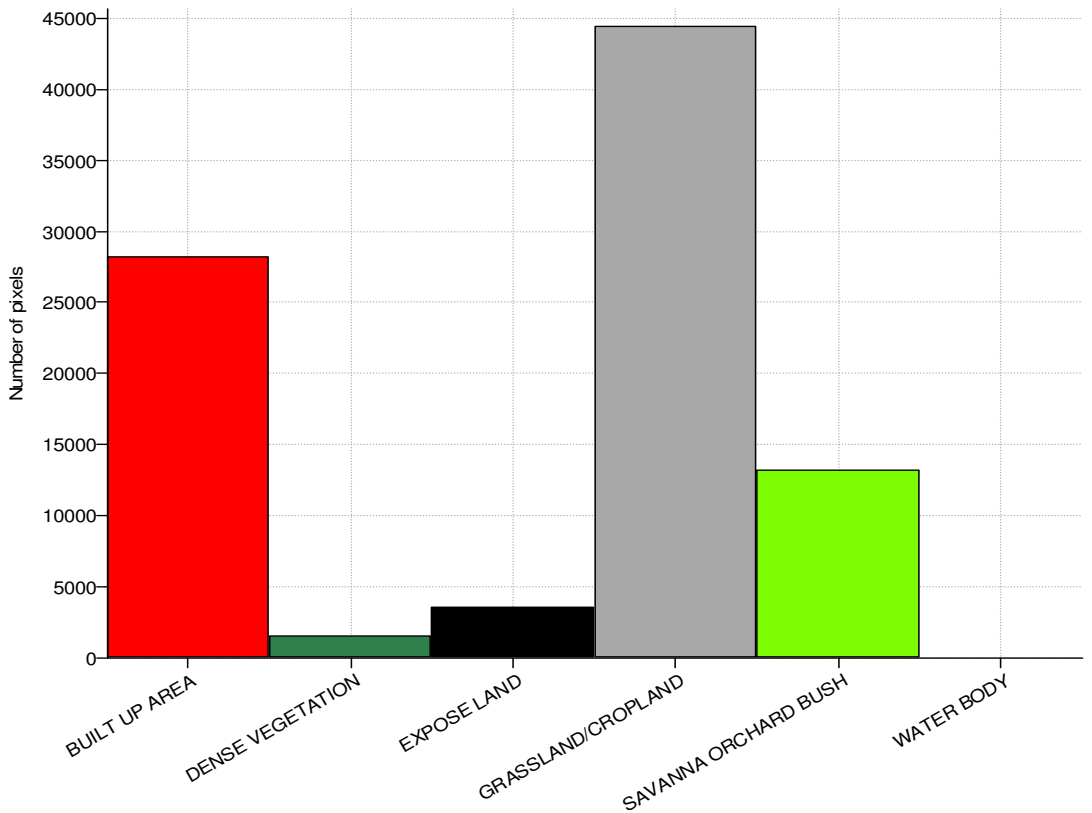

Figure 8: Histograms 2012 (DMC) Showing Land Uses in Lapai 
Ethiopian Journal of Environmental Studies and Management Vol. 8 (Suppl. 2) 2015

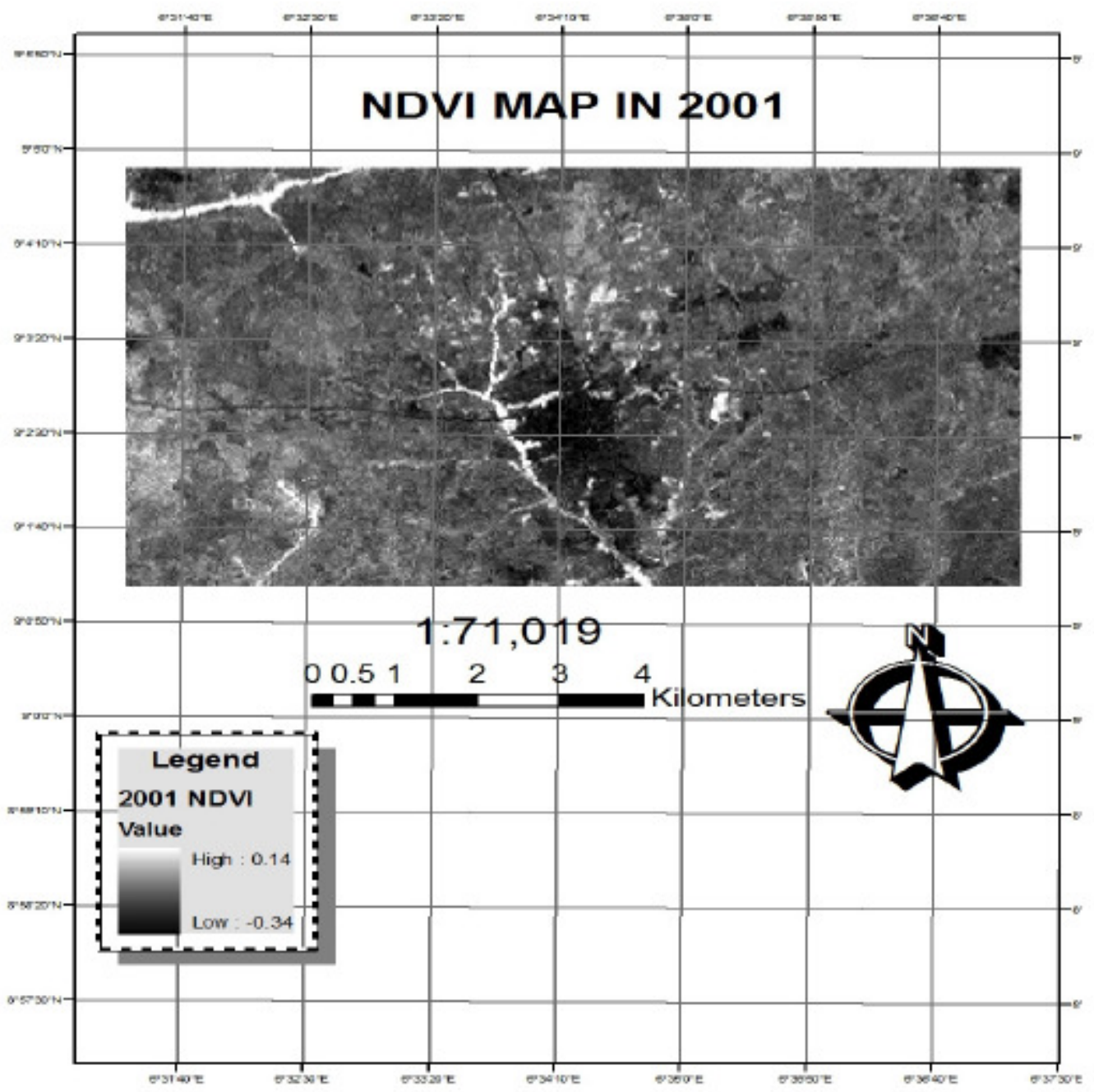

Figure 8: NDVI Map in 2001 


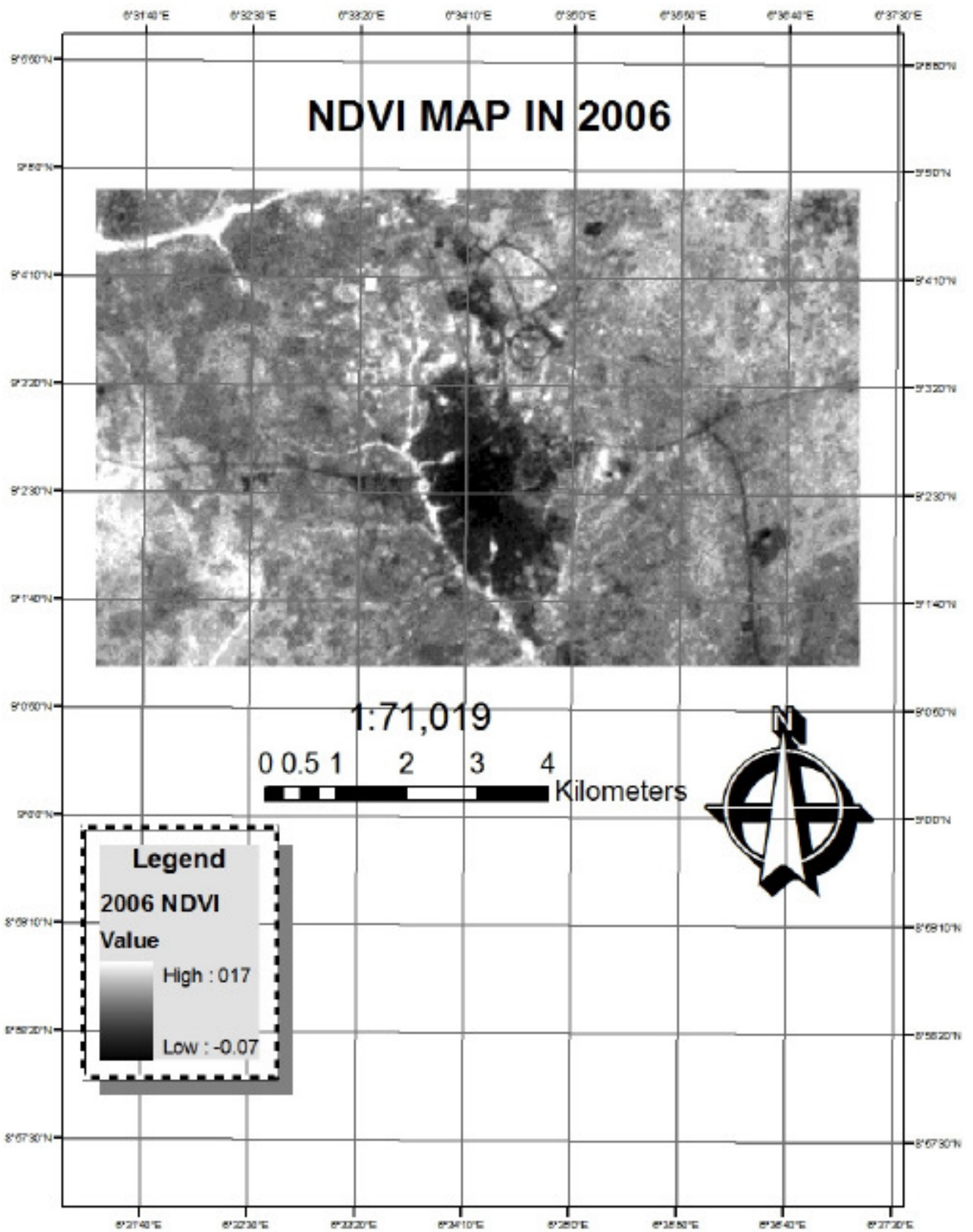

Figure 9: NDVI Mao in 2006 


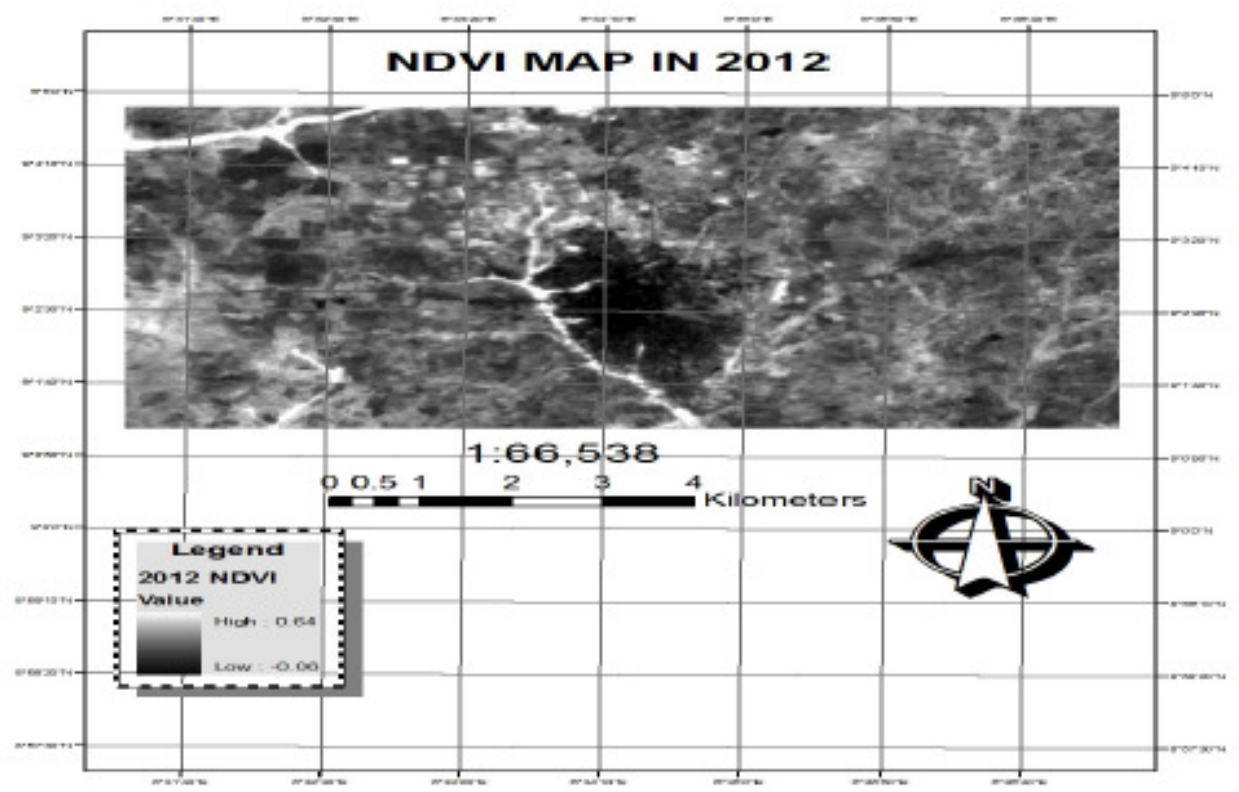

Figure 10: NDVI Map in 2012

Figures 8,9 and 10 above show that high reflectance of vegetation was seen in 2012 image of the study area, with increase in NDVI values. Conversely, vegetation reflectance is low in 2001 image, likewise in NDVI value. This is connected to the fact that the dense forest is still existing and as create as a result of that development has not yet reach the north west and south west that consist of the dense vegetation, so the forest have low reflectant in 2001 and high reflectance in 2012, but from the center of the town has a low reflectance value because of the massive infrastructural development going on in the town and the middle of the town which has the savanna orchard bush and grassland/cropland have high reflectance, further more the minimum value of the reflectance in 2001 is -0.34 compare to that of 2012 which is -0.10 and this explain the fact there is less factors in 2001 that have low value but in 2012 there is some factors that reflect very low value.

\section{Accuracy of Image Classification}

The overall accuracy of the land cover classification for the 2001, 2006 and 2012 $94.24 \%, 97.70 \%$ and $95.25 \%$ respectively. Generally, the frequency of confusion of classification was low but did occur. Savanna orchard bush were sometimes confused with both dense Forest and Grassland/cropland.

Table 3.1 Confusion matrix for 2001 classification

\begin{tabular}{llllllll}
\hline & BUA & DV & EL & GCL & SOB & WB & ACCURACY \\
\hline BUA & 539 & 0 & 0 & 10 & 0 & 0 & 0.98 \\
DV & 0 & 116 & 0 & 1 & 4 & 0 & 0.96 \\
EL & 0 & 0 & 50 & 0 & 0 & 0 & 1 \\
GCL & 3 & 0 & 0 & 601 & 15 & 0 & 0.97 \\
SOB & 0 & 59 & 0 & 12 & 395 & 0 & 0.85 \\
WB & 0 & 0 & 0 & 0 & 0 & 0 & 0 \\
RELIABILITY & 0.99 & 0.66 & 1 & 0.96 & 0.95 & 0 &
\end{tabular}

*Note *BUA-Built up Area, *DV-Dense Vegetation, *EL-Expose Land, *GCL-Grass/Cropland, *SOB-Savanna Orchard Bush, *WB- Water Body. 
Average Accuracy: $\quad 95.18 \%$

Average Reliability: $91.49 \%$

Overall Accuracy: $\quad 94.24 \%$

Table 3.2: Confusion matrix for 2006 classification

\begin{tabular}{llllllll}
\hline & BUA & DV & EL & GCL & SOB & WB & ACCURACY \\
\hline BUA & 540 & 0 & 0 & 9 & 0 & 0 & 0.98 \\
DV & 0 & 117 & 0 & 1 & 3 & 0 & 0.97 \\
EL & 0 & 0 & 50 & 0 & 0 & 0 & 1 \\
GCL & 4 & 0 & 0 & 686 & 15 & 0 & 0.97 \\
SOB & 0 & 7 & 0 & 0 & 264 & 0 & 0.97 \\
WB & 0 & 0 & 0 & 0 & 0 & 0 & 0 \\
RELIABILITY & 0.99 & 0.94 & 1 & 0.99 & 0.94 & 0 &
\end{tabular}

*Note *BUA-Built up Area, *DV-Dense Vegetation, *EL-Expose Land, *GCL-Grass/Cropland, *SOB-Savanna Orchard Bush, *WB- Water Body.

Average Accuracy: $\quad 97.96 \%$

Average Reliability: $97.16 \%$

Overall Accuracy: $\quad 97.70 \%$

Table 3.3: Confusion matrix for 2012 classification

\begin{tabular}{llllllll}
\hline & BUA & DV & EL & GCL & SOB & WB & ACCURACY \\
\hline BUA & 1539 & 0 & 0 & 1 & 0 & 0 & 1 \\
DV & 0 & 94 & 0 & 0 & 4 & 0 & 0.96 \\
EL & 0 & 0 & 178 & 1 & 0 & 0 & 0.99 \\
GCL & 3 & 0 & 0 & 378 & 51 & 0 & 0.88 \\
SOB & 0 & 5 & 0 & 64 & 395 & 0 & 0.85 \\
WB & 0 & 0 & 0 & 0 & 0 & 0 & 0 \\
RELIABILITY & 1 & 0.95 & 1 & 0.85 & 0.88 & 0 & \\
\hline
\end{tabular}

*Note *BUA-Built up Area, *DV-Dense Vegetation, *EL-Expose Land, *GCL-Grass/Cropland, *SOB-Savanna Orchard Bush, *WB- Water Body.

Average Accuracy: $\quad 93.58 \%$

Average Reliability: $93.53 \%$

Overall Accuracy: $\quad 95.25 \%$

Changing pattern of vegetation 


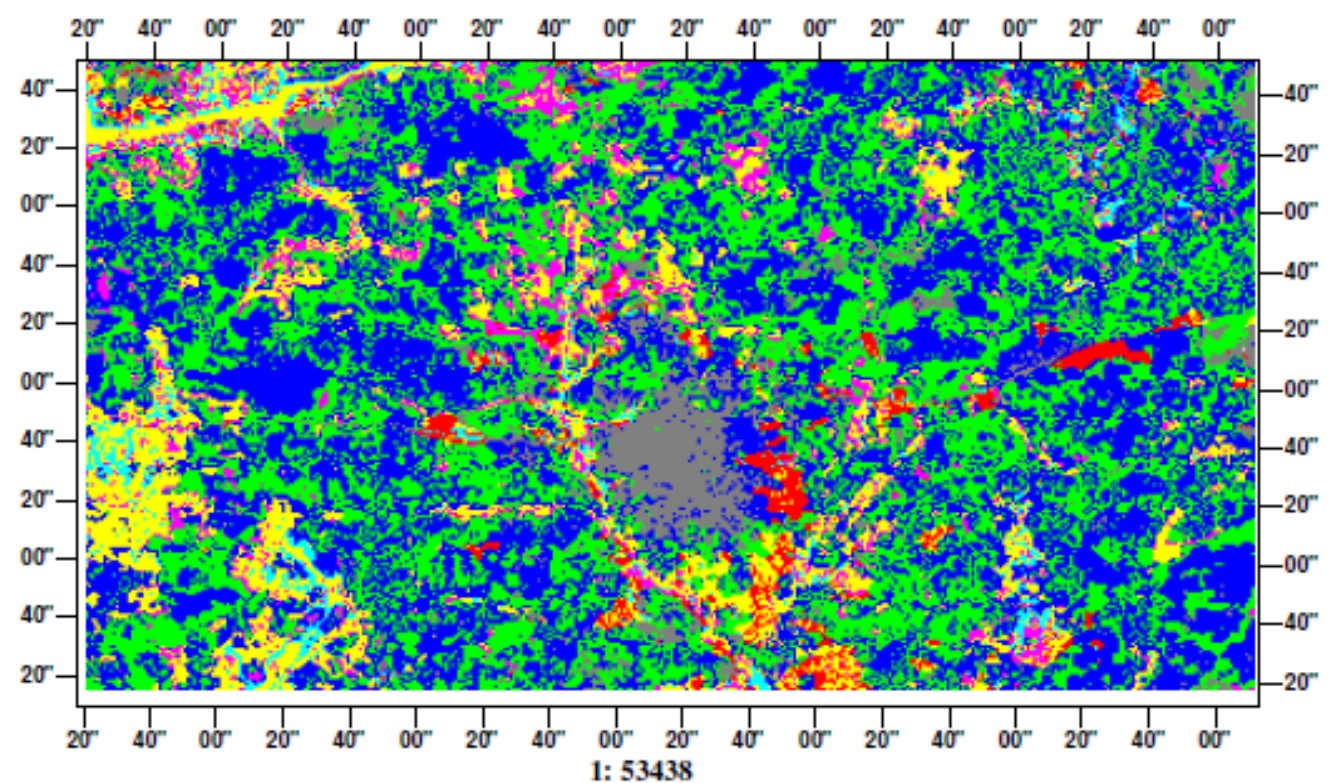

Figure 11: Overlay of 2001 and 2012 images

Table 4: Vegetation change matrix per pixel (2001 - 2012)

\begin{tabular}{lllllll}
\hline & BUA & DV & EL & GCL & SOB & WB \\
\hline BUA & 2950 & 0 & 149 & 611 & 105 & 0 \\
DV & 360 & 1021 & 156 & 1792 & 1731 & 0 \\
EL & 1416 & 32 & 568 & 1539 & 344 & 0 \\
GCL & 18232 & 75 & 1872 & 25299 & 3773 & 0 \\
SOB & 5226 & 337 & 744 & 15158 & 7187 & 0 \\
WB & 0 & 0 & 0 & 0 & 0 & 0 \\
\hline
\end{tabular}

*Note *BUA-Built up Area, *DV-Dense Vegetation, *EL-Expose Land, *GCL-Grass/Cropland, *SOB-Savanna Orchard Bush, *WB- Water Body.

\section{Result and Discussion}

Vegetation maps of the study area produced from the different satellite image obtained, which help in describing the various vegetation changes that has occurred from 2001 to 2012. The analysis was based on the land cover map produced and the NDVI values obtained from the NDVI maps produced. The results are presented in the form of maps, charts and statistical tables. They include the static change and accuracy of each image, Vegetation change, in particular, features strongly as both a contributor (clearing) to anthropogenic ecosystem hazards and a panacea (planting) for dealing with their adverse consequences. The functional role of vegetation has been recognized in the study (wind breaks, salinity and erosion control, greenhouse gas assimilation) but this role is rarely appreciated in cityscapes. Many professional urban vegetation designers, planners and managers as well as many individuals the general community of landholders, have long appreciated the amenity value of vegetation. The result reveal in table 2, 3, and 4 above represents the static area of each land cover category for each study year. Built-up in 2001 occupies the least class with just $4.21 \%$ of the total classes. This may not be unconnected to the fact that the town (lapai) was not yet made the town to be sited the state university. Also, 
farming seems to be practiced moderately, occupying $54.31 \%$ of the total classes in 2001. This may be due to the fact that the city is still in a traditional setting where farming seems to form the basis for living. In 2006, there is an increase in built up area and savanna orchard bush which occupies about $6.54 \%$ and $43.49 \%$ respectively, causing a decrease in the rest of the land cover type and this can be attributed to the starting face of the establishment of the state university, some of the dense vegetation are converted to a savanna orchard bush. From table 2, there seems to be a negative change i.e. a reduction in farm land between 2001 and 2012. This may not be unconnected to the change in the economic base of the city from farming to other white collar jobs as a result of the establishment of the state university. Subsequently, built-up land increased by $26.87 \%$ whiles the dense vegetation, savanna orchard bush, and grassland/cropland and expose land decreased by $3.96 \%, 17.11 \%, 5.35 \%$, and 0.45 respectively. Many projects were embarked on after the establishment of the state university and this result to the attraction of a lot of people to the area thus contributing to the physical expansion of the town as evident in the increased built up area from $4.21 \%$ to $31.08 \%$ of the total class.

NDVI is an excellent and widely used method for crop growth and condition assessment (Rahman et al., 2004). For this study NDVI calculation was performed to produce NDVI images for the three periods. Figure. 8and 9 show the various periods of NDVI images likewise figure 10 shows the reflectant value of the vegetation. It shows that high reflectance of vegetation was seen in 1986 image of the study area, with increase in NDVI values. Conversely, vegetation reflectance is low in 2001 image, likewise in NDVI value. Fig. 10 shows the changing pattern of vegetation for both periods been crossed. So, it may be said that the vegetation change was mainly due to increase in population, as a result of anthropogenic activities.

\section{Summary and Conclusion}

Green coverage is one of the most important factors for sustaining life and the living environment for any rapidly growing town, like Lapai; not only for preserving sustainable human habitat but also for safeguarding from the detrimental effects of urban pollution and Urban Heat Island (UHI). The study has indicated the potential use of remote sensing data in studying vegetation change. GIS techniques integrated in this study has proved beyond doubt its capabilities of spatial analysis. In this study LANDSAT images and Nigeriasat-2 sensor were used satisfactorily for the identification of vegetation. It was observed that the area under, vegetation changed during 20012012 remarkably, decrease in vegetation has been as a result of anthropogenic activities in the study area. . If this process of change in vegetation cover continues at the same rate, there is a possibility that within no longer period of time there will be a severe mismanagement of land, and the impact could become severe especially on agriculture, and the environment. In conclusion for detecting changes in areas based on a subject e.g population increase, vegetation etc, over a period of years both spatial and in quantitative way, integrating remote sensing data and GIS techniques will be useful.

\section{Recommendation}

Analysis of local patterns of vegetation change as carried in this study could provide relevant information for policy makers who are responsible for land use planning and environmental protection. As vegetation change is multicausal, a set of 
policy prescriptions is required to address the adverse effects of the phenomenon.

Decline in the vegetation underscores the need for coercive environmental protection policies to relieve human pressure on vegetation resources.

Phenomenal agricultural expansion at the expense of forest leading to nutrient mining should call for agricultural intensification-related policy initiatives to discourage expansion of cultivation on fragile lands. Such intensification strategies should address sustainable land cover management and farming techniques that replenish soil nutrients.

Afforestation is needed to restore the degraded parts of the landscape. The establishment of vigorous vegetation will lead to an increase in biomass.

Afforestation strategies in Niger should involve the choice of appropriate species that are well adapted to the environment.

\section{References}

Campbell .J.B, (1987). 'Introduction to Remote Sensing', New York: The Guilford Press. George Xian, Mike Crane; 'Evaluation of Urbanization Influences on Urban Climate with Remote Sensing and Climate Observations', SAIC/ USGS National Center for Earth Resources Observation and Science, Sioux falls, SD57198.

Dimyati, M. (1995). An Analysis of Landuse/Landcover Change Using the Combination of MSS Landsat and Landuse Map. A Case Study of Yougyakarta Indonesia. International Journal of Remote Sensing, 17(5): 937-944.

Campbell. J.B. (2002). 'Introduction to Remote Sensing (third edition); Guilford press, a division of Guilford Publication, Inc 72 spring street New York. NY10012.
Lillesand T.M. and Keifer, W. (1994). 'Remote Sensing and Image Interpretation'; New York: John Wiley.

Rejaur Rahman, A.H., Hedayutul Islam, M.D. and Hassan, S. (2004). 'Change Detection of Winter Crop Coverage and the Use of Landsat data with GIS'; The Journal of GeoEnvironment Vol.4, PP1-13.

National Population Commission (2006). Fedreal Republic of Nigeria Officail Gazette Legal Notice on Publication of the 2006 Census Report, No9. 4, vol. 94, Lagos-19th January, 2006.

NASRDA (2012). National Space Research and Development Agency in Abuja, Nigeria

Abdul Hakeem, K. and Thiruvengadachari, S. (1998). Satellite derived Crop Calender for Canal Operation Schedule in Bhadra project command area, India. International Journal of Remote Sensing, 19: 2865- 2876.

Rejaur Rahman, M.D. and Ataur (2004). 'NDVI Derived Sugar cane area Identification and crop condition Assessment', planplus, Vol.2, Urban and Rural Planning Discipline, Khula University, Bangladesh.

Rosenberg, D.B. and Freedman, S.M. (1984). Application of a Model of Ecological Succession to Conservation and Land-Use Management, Environmental Conservation, 11: 323- 329

Singh, A. (1989). Digital Change Detection Techniques Using Remotely Sensed Data. International Journal of Remote Sensing, 10(6): 989-1003.

Singh, A. (1989). 'Review Article: Digital Change Detection Techniques using Remotely Sensed Data'. International Journal of Remote Sensing, 10: 989- 1003. 